\title{
Transit Stops and Stations: Transit Managers' Perspectives on Evaluating Performance
}

\author{
Michael Smart ${ }^{1}$, Mark A. Miller, ${ }^{1,2}$, and Brian D. Taylor ${ }^{1}$ \\ ${ }^{1}$ University of California, Los Angeles \\ ${ }^{2}$ University of California, Berkeley
}

\begin{abstract}
Passengers, transit managers, adjacent businesses and residents, and local governments all can have strong, and sometimes conflicting, ideas about what makes a good transit stop or station. This paper examines stops and stations from the transit agency's perspective; transit managers must consider both the logistical and political factors inherent to transit operations as well as the perspectives of customers they seek to attract and retain. An online survey of U.S. transit systems was administered to estimate magnitudes of managers' perceived importance of an array of stop/station attributes and objectives to provide a quantitative and objective summary of the collective wisdom of U.S. transit managers. This complements the mostly qualitative and case-study research on this topic. Using a sophisticated nonparametric ranking method, an estimate of the transit agency's perspective on stops and stations was produced. Respondents clearly believe that safety and security are most important to a good stop/station, followed by ease of transferring and cost-effectiveness. Comfort and aesthetic factors rank much further below these.
\end{abstract}

\section{Introduction}

Unlike door-to-door travel by foot, bicycle, taxi, or private vehicle, public transit passengers typically must wait for and transfer between buses and trains. As such, 
the travel time spent outside of transit vehicles constitutes an important, and under-studied, part of transit travel. However, it is rarely a simple matter to plan a good transit stop or station. Typically, many stakeholders have a say in the siting, design, and operation of the facility. It is often an intricate interaction of various stakeholders' desires and constraints that results in the final design and siting of a stop or station. Often, so many stakeholders vigorously debate the location, scale, and character of transit stops and stations that frustrated practitioners conclude, "It's all just politics!"

In this paper, we attempt to clarify and quantify the objectives of the stakeholder who must balance the often-competing views on stops and stations-the transit agency. A systematic understanding of how transit managers view the relative importance of a wide array of transit stop and station attributes can help practitioners and scholars understand how siting, design, and operations decisions are made-and how they could be made better. While others have compiled best practices guides for transit agencies (see, for example, Fitzpatrick, Hall et al. 1996), our findings represent the collective wisdom and expertise of U.S. transit managers and provide a rigorous quantitative analysis of the perceived importance of various stop and station attributes.

Research has shown that, when transit connectivity is poor, waits and transfers become burdensome for transit users and discourage transit use. Poor stop and station connectivity results in trips that are

... frustrating, time-consuming, and costly, lowering service quality for users and making transit unattractive for new customers.... [Conversely, good connectivity is] reflected in a convenient and "seamless" transit system by reducing travel times, providing more reliable connections, making it easier to pay and ensuring that transfers are easy and safe. (Metropolitan Transportation Commission 2006)

The scope and scale of wait/transfer sites vary significantly, from hundreds of thousands of simple bus stops around the U.S. marked by little more than a small sign on a pole, to elaborate and architecturally significant multi-modal commercial hubs, like Union Station in Washington, D.C. The attributes of these wait/ transfer facilities differ in many ways: physical size and configuration; number of lines, agencies, and modes served; traveler amenities; operating costs; and effects on neighboring communities. Systematically evaluating such heterogeneous places thus poses a significant analytical challenge. 
Furthermore, perceptions of just what are the most important aspects of transit stops and stations can vary considerably depending on the stakeholders involved. These include:

- passengers

- adjacent businesses and residents

- local governments

- transit agencies (the focus of this paper)

Passengers are the raison d'etre of transit travel and their perceptions and needs are central (Committee on Intermodal Transfer Facilities 1974). But beyond passenger needs, transit stops and stations must also meet operational objectives. These include the provision of vehicle queuing and staging areas, adequate road/ rail network access, adequate vehicle/passenger separation, driver break facilities, and so on. When a transit agency directly controls property on which a stop or station sits, it can largely control stop/station attributes to accommodate operational requirements (Vuchic and Kikuchi 1974). But more often, stops and stations are partially or fully controlled by other governmental agencies-most frequently, local governments that control sidewalks - who may have interests different than, and sometimes at odds with, those of transit agencies (Law and Taylor 2001).

No transit stop or station is truly a stand-alone facility; it relates to and interacts with adjacent businesses and homes, providing access as well as generating traffic, noise, emissions, and other negative externalities. Over the longer term, the facility can affect the type and level of adjacent development, sometimes significantly (Vuchic and Kikuchi 1974). Indeed, in one survey of transit agencies, respondents named the provision of a civic facility and assistance with downtown development as objectives of transit transfer facilities (Hocking 1990).

All of these various perspectives are important in the design and siting of transit stops and stations, as they should be. In this paper, we focus specifically on the transit agencies' objectives for transit stops and stations to update the literature on the transit agencies' perspectives, much of which is currently 30 years old and anecdotal in nature. We further introduce a more sophisticated attribute ranking system than has been used in past research to provide scholars and practitioners a clear picture of transit managers' collective wisdom on stops and stations. Finally, we add to the existing literature by introducing new objectives into the ranking of transit facilities, such as the development of "greener" facilities. 


\section{Previous Work}

The transit connectivity literature consists of two primary components that have not been well integrated: (1) the behavioral and perceptual aspects of waiting and transferring at stops and stations and (2) the physical and geometric design of transfer facilities and their operations.

The travel behavior literature emphasizes transit riders' perceptions of time, and how these perceptions differ when in vehicles, walking, or waiting. Generally, time spent walking and waiting is perceived by travelers as more onerous than time spent in a transit vehicle. There is considerable variability in how much more onerous waiting and walking is, and this depends, in part, on the environment in which one is walking and waiting. We performed an extensive review of the travel behavior literature as part of the larger project from which this paper was based and produced a conceptual framework for determining the generalized cost of waiting and transferring (Iseki and Taylor 2007).

But this behavior research, while extensive and often sophisticated, is seldom referenced in the literature on transit stop and station design or operations. Prior to the mid-1970s, a "rule of thumb" approach was employed for transit station design based on little formal evaluation. This began to change as architects, engineers, and planners developed more formalized and comprehensive approaches to transit stop and station design (Hoel and Rozner 1976; Hoel, Demetsky, and Virkler 1976).

This research, sponsored by the U.S. Department of Transportation, used systems analysis to develop a methodology for planning, designing, and evaluating transit stops and stations (Hoel, Demetsky, and Virkler 1976; Demetsky, Hoel, and Virkler 1976, 1977). This new methodology accounted for the differing perspectives of stakeholders in the development of a transit interface facility design.

However, almost all early research simply lists factors or attributes considered important by various stakeholders, with little in the way of explanatory information to help readers understand how such factors interact, their tradeoffs, or their relative importance. For example, Vuchic and Kikuchi (1974) include the following transit agency-related factors that the design of transfer facilities must satisfy: minimum operating cost, adequate capacity, and flexibility of operation. Other research cited additional objectives, such as safety maximization, energy efficiency, and the provision of protection from the weather (Hoel, Demetsky, and Virkler 1976; ITE Technical Council Committee 5C-1A 1992). 
Horowitz and Thompson $(1994,1995)$ acknowledge that the evaluation of transfer facilities requires an examination of both the costs and benefits of various design elements. Their research is the only example we identified that goes beyond a simple listing of factors by ranking the relative importance of the transit agencyrelated factors, in addition to passenger- and community-related factors. The authors developed a list of 70 broadly-worded objectives from all three stakeholder perspectives. These were then rank-ordered by their mean rating on a scale of 0 (Not Important) to 10 (Extremely Important). They found that safety, security, and ease of transferring were the highest-ranked transit agency objectives, while others (cost minimization, joint development) ranked much lower.

Our review of the literature on transit stop/station design identified a set of transit agency-related factors, which we organized into four general categories:

\section{Costs and Revenues}

Clearly, the costs of operating a transit transfer facility are important. A few of the individual fiscal factors identified from the literature include total cost, operating cost, maintenance, and investment cost (obtaining an efficient return on incremental investment) (Vuchic and Kikuchi 1974; Hoel, Demetsky, and Virkler 1976; Demetsky, Hoel, and Virkler 1976; ITE Technical Council Committee 1992; Horowitz and Thompson 1994, 1995).

\section{Institutional and Coordination}

Many stops and stations host multiple lines, modes, and/or service providers and thus require coordination on many levels, including transfer fares, schedules, and information dissemination. Generally, there is only one source from the literature (Horowitz and Thompson 1994, 1995) that explicitly identifies institutional issues as objectives from the transit agency perspective; they are "minimize institutional barriers to transferring" and "maximize coordination of transfer scheduling," ranked 4th and 11th, respectively (out of 70)-much higher than cost concerns in this study.

\section{Passenger Processing}

Passenger processing objectives refer to the functional components of stops and stations together with their arrangements at the stop or within the station. Basic functional stop/station components consist of internal pedestrian movement facilities and areas, line haul transit access area (entry control and fare collection; loading and unloading of passengers), and communications (Hoel, Demetsky, and 
Virkler 1976; Demetsky, Hoel, and Virkler 1976; ITE Technical Council Committee 1992).

\section{Environment}

The environmental quality of a transit stop or station involves aspects with which facility users (including agency employees) associate their comfort and convenience (e.g., weather protection), safety (e.g., accident reduction), and security (e.g., security cameras) (Hoel, Demetsky, and Virkler 1976; Demetsky, Hoel, and Virkler 1976).

Table 1 summarizes the transit agency-related factors that we identified from the literature (after removing redundancies). These factors formed the starting point for our survey design, discussed below. While we attempted to create an exhaustive list of stop/station factors, we anticipated that transit managers might have additional insight on important factors related to transit stops and stations. We therefore included in our survey instrument an opportunity for transit managers to identify additional factors not listed here. Additionally, our telephone surveys allowed transit managers a forum to discuss factors important to the siting, design, operation, and maintenance of transit stops and stations. We discuss these respondent-generated stop/station factors below.

\section{Methodology}

Given the 26 stop/station evaluation factors identified in the literature and summarized in Table 1, we developed and administered a survey of U.S. transit agencies to:

1) update the now 30-year old evaluation objectives so these factors reflect current circumstances

2) identify other factors important to transit agencies today not identified in the literature

3) understand the priorities that transit agencies place on these factors to estimate their relative importance

The survey prompted respondents to consider transit stops and stations in general, rather than focus on one stop in particular. This, we hope, discouraged respondents from basing their responses on a single stop or station that might be noteworthy for one reason or another (e.g., a new or large facility, or one that 


\section{Table 1. Transit Agencies' Perspective Evaluation Objectives}

\begin{tabular}{|c|c|}
\hline Categories & Evaluation Objectives \\
\hline \multirow{12}{*}{$\begin{array}{l}\text { Fiscal / Costs \& } \\
\text { Revenues }\end{array}$} & Minimize total, operating, maintenance, and investment costs \\
\hline & Achieve elimination of hazardous materials \\
\hline & Minimize wasted space \\
\hline & Maximize income from non-transport activities \\
\hline & Minimize negative impact on existing transportation services \\
\hline & Maximize joint development \\
\hline & Achieve property rights \\
\hline & Maximize flexibility for expansion \\
\hline & Minimize fare inconsistencies \\
\hline & Maximize ease of operations of modes \\
\hline & Utilize energy efficiently \\
\hline & Maximize flexibility of operation \\
\hline \multirow{2}{*}{$\begin{array}{l}\text { Institutional and } \\
\text { Coordination }\end{array}$} & Minimize institutional barriers to transferring \\
\hline & Maximize coordination of transfer scheduling \\
\hline \multirow{8}{*}{$\begin{array}{l}\text { Passenger } \\
\text { Processing }\end{array}$} & Maximize equipment reliability \\
\hline & Efficiently collect fares and control entry \\
\hline & Maximize safety \\
\hline & Efficiently process flows \\
\hline & Provide adequate space \\
\hline & Minimize queues \\
\hline & Minimize pedestrian-vehicle conflicts \\
\hline & Eliminate physical barriers \\
\hline \multirow[t]{4}{*}{ Environment } & Provide a safe and secure environment \\
\hline & $\begin{array}{l}\text { Provide proper physical environment (lighting, air quality, } \\
\text { temperature, aesthetics, and cleanliness) }\end{array}$ \\
\hline & Provide restrooms, first-aid stations, public telephones \\
\hline & Provide protection from the weather \\
\hline
\end{tabular}

had proven particularly successful or problematic). In addition to this survey, we also conducted telephone interviews with a smaller sample of U.S. transit agencies to gain further insight into their perspective, as well as to gather illustrative anecdotes.

\section{Designing the Survey Instrument}

Through our online survey, we gathered (1) information about the respondent and transit agency; This first section was used to link the respondents' answers with outside data on the agency (for example, number of routes and service 
area population), and (2) transit agencies' views of which factors are important at stops and stations. In designing the survey, we utilized a 4-point Likert scale, asking transit agencies how important various evaluation factors are: Very Important, Important, Somewhat Important, or Not Important. Respondents also could select Not Applicable/Do Not Know. We based the inventory of factors on our literature review, summarized in Table 1. Some objectives were duplicative, and in these instances, we removed duplicates and grouped these objectives into one broadly worded category. We then supplemented these with a few others based on our discussions with individual transit managers, including "maximize vehicle maneuverability," "maximize environmental friendliness of station/facility ("green" station/facility), and "provide a break area for vehicle operators." The survey also allowed respondents to add factors they deemed important but that the survey did not list.

\section{Identifying the Participants and Administering the Survey}

We used the Federal Transit Administration's 2005 National Transit Database to identify 406 potential participants, all of which operated at least one fixed-route/ fixed-schedule service. Invitations to participate in the survey (and two reminders) were sent by e-mail to potential respondents along with a link to the survey website. Respondents had over five weeks to complete the survey.

\section{Analysis and Findings}

\section{Respondents}

About half (197) of our invitees accessed the survey website. Of these, several response sets were excluded from analysis:

- 6 invitees opted out of participating after accessing the survey site

- 16 invitees agreed to participate but then provided few or no responses

Thus, 175 response sets remained for analysis, for a response rate of 43 percent. Additionally, we contacted 40 agencies to participate in in-depth telephone interviews typically lasting more than one hour. We selected these agencies by a weighted sampling methodology, with the probability of inclusion weighted by the agency's annual ridership figures. Of these, 16 agencies participated, for a response rate of 40 percent. These 16 agencies represent a wide spectrum of agency types, with small, medium, and large agencies at the municipal, regional, and state level, as well as one university transit agency. 
Survey respondents varied in several important ways. For example, while most respondents worked at agencies that operate buses (and demand-responsive vans) only, 23 respondents (13\%) came from agencies with rail service and 4 respondents' agencies (2\%) operated rail only. The number of vehicles in service also varied greatly. A total of 67 respondents (38\%) worked at agencies operating with fewer than 50 vehicles in revenue service, while 5 respondents (3\%) were at very large agencies, with more than 2,000 vehicles in revenue service.

While our respondents closely reflected the universe of U.S. fixed-route transit providers in most ways, there was one way in which responses appear nonrandom. Compared with all U.S. transit agencies, the survey respondents tended to hail from larger metropolitan areas. The median service area population for our respondents was 303,000, while for the universe it was 145,000.

\section{Threats to Validity}

While we are confident that the research design we chose provides robust results, there are several threats to validity that are worth mentioning. For example, one may expect that our respondents tended to be workers at transit agencies who had, on average, more inclination to reply than did others-perhaps because they had recently experienced a major success or setback in their work and felt the desire to share that with the research community. Similarly, it is likely that invitees who simply had more time were more likely to respond. However, we do not expect that these various paths of self-selection lead to a significant systematic bias toward one result or another.

It is also likely that respondents tended to emphasize the importance of attributes that are more difficult or costly to provide and therefore tend to be done poorly. This would tend to skew the results of our survey to suggest that things that are harder to provide are more important. This is an unfortunate consequence of all stated-importance research, and we have attempted to bear this in mind when interpreting our results.

Finally, the bulk of our analysis groups all responses together. There may be cause to believe that responses would vary significantly by the type of the respondent's agency-large or small, bus- or rail-only, or even geographic location. Indeed, there are some differences among various subgroups of respondents, though these are, for the most part, minor. Where appropriate, differences among subgroups are highlighted in the analysis. Because differences by modes operated are likely of great interest to many readers, we highlight these in Table 2 below. The differences 
between agencies with at least some rail service and those operating buses only were remarkably minor. While these differences are certainly worth noting, what we find most noteworthy from this analysis is the consistency across respondent subgroups. This suggests that, in the views of transit managers, the underlying factors affecting the performance of transit stops and stations are strikingly similar from system to system, mode to mode, and station to stop.

\section{Table 2. Variables with a Statistically Significant Difference}

\begin{tabular}{|l|c|c|c|c|}
\hline OBJECTIVE & NO RAIL & HAS RAIL & DIFF. & SIG. \\
\hline Provide restrooms, first-aid supplies, and public telephones. & 2.25 & 2.74 & -0.49 & $* * *$ \\
\hline Provide protection from the weather. & 1.60 & 1.96 & -0.36 & $* * *$ \\
\hline Maximize coordination of scheduling to accommodate transfers. & 1.43 & 1.75 & -0.32 & $* * *$ \\
\hline Maximize reliability of station/stop equipment. & 1.56 & 1.33 & 0.23 & $* * *$ \\
\hline
\end{tabular}

\section{Responses}

Participants were asked to rate 23 separate attributes connected with the planning, siting, operation or maintenance of transit stops, stations and transfer facilities using a 4-point Likert scale. Table 3 shows the mean attribute scores and standard deviations for all respondents. An average score of 1.00 would indicate that all respondents rated the attribute as Very Important, and an average score of 4.00 would indicate that all respondents rated the attribute as Not Important. As is typical with Likert-scale measurement, significant response clustering is evident, with nearly all average scores falling within the one-point interval $(1.40,2.40)$. This is due, in this case, to respondents' tendencies to rate most attributes as Important or Very Important.

The attribute "safety and security" was ranked most important by respondents, with an average score of 1.15 and a relatively small standard deviation of 0.39 . This score is considerably lower (more important) than the second-most important attribute, "minimize pedestrian-vehicle conflicts." Our telephone interviews supported this finding very clearly, with one interviewee commenting that safety "trumps all." Many interviewees related anecdotes in which safety and security concerns forced agency planners to design a station in such a way that other objectives were compromised. One respondent from a city with a "very high murder rate" told us that police are present at station design meetings, and that personal safety concerns always outweigh aesthetic, design, and passenger comfort concerns. 


\section{Table 3. Average Objective Scores}

\begin{tabular}{|c|c|c|c|c|}
\hline & \multirow{2}{*}{ OBJECTIVES } & \multirow{2}{*}{$\begin{array}{l}\text { MEAN } \\
\text { SCORE }\end{array}$} & \multirow{2}{*}{$\begin{array}{l}\text { STD } \\
\text { DEV }\end{array}$} & \multirow[b]{3}{*}{ i } \\
\hline & & & & \\
\hline 1 & Provide a safe and secure environment. & 1.15 & 0.39 & \\
\hline 2 & Minimize pedestrian-vehicle conflicts. & 1.41 & 0.62 & \multirow{10}{*}{ 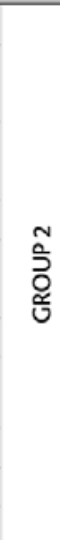 } \\
\hline 3 & Maximize coordination of scheduling to accommodate transfers. & 1.48 & 0.61 & \\
\hline 4 & Minimize total cost of operations (including maintenance costs). & 1.50 & 0.67 & \\
\hline 5 & Maximize reliability of station/stop equipment. & 1.52 & 0.66 & \\
\hline 6 & $\begin{array}{l}\text { Provide a comfortable physical environment with respect to lighting, } \\
\text { temperature, and cleanliness. }\end{array}$ & 1.54 & 0.63 & \\
\hline 7 & Provide adequate station/stop space. & 1.54 & 0.62 & \\
\hline 8 & $\begin{array}{l}\text { Minimize institutional barriers to transferring such as transfer fares, lack of } \\
\text { information or poor coordination of schedules. }\end{array}$ & 1.57 & 0.66 & \\
\hline 9 & Efficiently process rider flows. & 1.63 & 0.63 & \\
\hline 10 & Maximize vehicle maneuverability (turning radii, etc). & 1.64 & 0.77 & \\
\hline 11 & Provide protection from the weather. & 1.64 & 0.72 & \\
\hline 12 & Efficiently collect fares and control entry to station/stop/vehicle. & 1.76 & 0.71 & \multirow{7}{*}{$\begin{array}{l}m \\
\stackrel{m}{0} \\
\text { ษับ }\end{array}$} \\
\hline 13 & $\begin{array}{l}\text { Maximize operational ease at the station or facility, e.g., vehicle maintenance, } \\
\text { vehicle storage, ticketing, baggage handling, and/or accounting. }\end{array}$ & 1.87 & 0.79 & \\
\hline 14 & $\begin{array}{l}\text { Maximize flexibility for expansion to handle an increase in demand or } \\
\text { addition of new modes. }\end{array}$ & 1.99 & 0.75 & \\
\hline 15 & Provide a break area for vehicle operators. & 2.03 & 0.83 & \\
\hline 16 & $\begin{array}{l}\text { Minimize fare inconsistencies, i.e., different fare rates across transit agencies } \\
\text { or inconsistent rates across like modes. }\end{array}$ & 2.12 & 0.94 & \\
\hline 17 & $\begin{array}{l}\text { Maximize environmental friendliness of station/facility ("green" } \\
\text { station/facility). }\end{array}$ & 2.17 & 0.79 & \\
\hline 18 & $\begin{array}{l}\text { Maximize joint development, i.e., involving the public and private sectors in } \\
\text { sharing the facility and its costs and revenues. }\end{array}$ & 2.21 & 0.89 & \\
\hline 19 & Provide restrooms, first-aid supplies, and public telephones. & 2.28 & 0.94 & \multirow{5}{*}{ 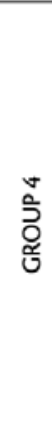 } \\
\hline 20 & Minimize queues. & 2.30 & 0.9 & \\
\hline 21 & $\begin{array}{l}\text { Minimize wasted space in station/stop design because large spaces increase } \\
\text { construction costs and require more maintenance, security, and } \\
\text { environmental controls. }\end{array}$ & 2.31 & 0.86 & \\
\hline 22 & $\begin{array}{l}\text { Minimize negative impact on existing transportation services, i.e., on transit } \\
\text { agencies who cannot participate or on transit agencies whose routes are } \\
\text { disrupted or whose routes face additional competition. }\end{array}$ & 2.37 & 0.91 & \\
\hline 23 & $\begin{array}{l}\text { Maximize income from non-transport activities, such as advertising and } \\
\text { vending. }\end{array}$ & 2.56 & 0.99 & \\
\hline
\end{tabular}


Respondents clearly believe safety and security to be more important factors than all others, with the most important (safety and security) and 2nd most important (minimize pedestrian conflicts) attributes relating to this topic. It appears that transit agencies often are willing to forgo other attributes in the pursuit of a safe environment; one telephone interviewee mentioned a station redesign that resulted in a safer environment for pedestrians, but which was far less aesthetically pleasing. Indeed, almost all telephone interviewees reported similar anecdotes.

After safety and security, the remaining attributes are all clustered relatively closely. The 2 nd through 11th ranked factors are closely bunched between 1.41 and 1.64. The remaining 12 factors are not as tightly bunched as the top dozen and are closer to 2.0 or 2.5 than 1.0 or 1.5. Table 3 divides the attributes measured in our survey into four groups: the top attribute with an average score near 1.0 (Group 1), and those attributes with average scores near 1.5, 2.0 and 2.5 on the Likert scale. We observe that lower-score (more important) attribute groups tend to contain more passenger-oriented attributes, while, further down the rank order, attributes tend to be more system- or transit agency-oriented or focus on facility externalities.

Ease of transferring was also an important factor; the 3rd most highly-ranked attribute was the coordination of scheduling to accommodate transfers. Several telephone interviewees from larger cities remarked that inter-agency coordination was particularly important for the provision of "seamless" transit service, while agencies in smaller regions focused on internal scheduling and the use of "pulse" systems.

Ranked 4th were cost-related factors, a subject about which our telephone interviewees had much to say. Many remarked that, by the time a project reaches the design phase, cost-considerations are "negligible" - that costs are fixed by that point. Other interviewees told us that costs associated with transit stops and stations tended to be minimal compared to costs associated with vehicles and labor. Rail agencies, however, tended to stress the importance of keeping costs down when constructing or rehabilitating stations, especially in older systems with "legacy" infrastructure.

Ranked 5th were considerations of equipment reliability. Rail agencies tended to rate this attribute much more important than did bus-only agencies, likely owing to their more frequent use of equipment in stations. It should also be noted that some confusion may have arisen around the attribute "equipment reliability," with 
respondents perhaps uncertain whether rolling stock or station equipment (our intention) was meant.

Comfort considerations and the provision of adequate space received nearly equal ratings (1.54), followed closely by the absence of institutional barriers to transferring. Most telephone interviewees mentioned that, while comfort considerations were important, safety concerns frequently required the use of, for example, uncomfortable seating.

At the other end of the spectrum, the "maximization of income from non-transport activities, such as advertising and vending" ranked least important, with an average score of 2.56 and a very high standard deviation of 0.99 . For some transit agencies, this factor was Very Important (26 cases); while for many others this factor was Not Important (29 cases). This large degree of variation may be due to the variability in agency income derived from advertising. Indeed, of respondent agencies, the ratio of non-transport to transport revenue varies greatly, with an average of 0.11:1 and a standard deviation of 0.24 (National Transit Database 2005). This likely reflects that oftentimes it is local governments that control advertising on bus benches, shelters, and even in off-street facilities. These local governmentsnot the transit agencies-therefore reap income from transit stops and stations. Thus, the disinterest of many respondents to the collection of non-transport revenues likely reflects that such revenues go to other entities (Law and Taylor 2001). Accordingly, respondents from agencies with high levels of non-transport income were slightly less likely to rate advertising revenue as "not important" than did respondents from other agencies, though this correlation is not statistically significant.

Similarly, the minimization of "negative impacts on existing transportation services," the "minimization of wasted space and queues," and the "provision of amenities such as restrooms and telephones" also ranked low on the list of attributes, at about 2.30 each. Our telephone interviews tended to support this finding, with several interviewees mentioning the impossibility of providing significant amenities at the bulk of their stops-hundreds of simple signs on poles on street corners.

Several questions elicited a large number of Not Applicable/Don't Know responses or received no answer at all. Respondents skipped "minimize negative impact on existing transportation services" 61 times (35\% of respondents), while 34 (19\%) skipped "minimize fare inconsistencies." Both of these questions pertain to operations that interface with other agencies; presumably, many respondent agencies 
operate in relative isolation, and this may account for significant non-response here.

In addition to the rating of listed attributes, respondents were given the opportunity to add attributes they felt were important to the siting, design, and operation of transit transfer facilities, and 39 respondents (22\%) did so. The three most frequently cited attributes among these responses were, respectively, "easy pedestrian accessibility to the transfer facility" (7 responses), "provision of real-time information through 'next-bus' or 'next-train' electronic signs" (6 responses), and the "centrality of the transfer facility siting" ( 4 responses), with respondents citing the need for "proximity to rider destinations" and locations in "urban centers rather than in remote locations." Another four respondents cited adherence to the accessibility requirements of the Americans with Disabilities Act. Our telephone interviewees added several other objectives we had not included in our survey, including even station spacing, transit-oriented development objectives, and system "legibility" (intuitive design).

The preceding analysis used mean Likert scores. A perhaps more suitable, though more complex, method of analysis is the non-parametric Friedman rank test, which accounts for differential usage of the Likert scale by respondents. The method produces rank values for each respondent's answers across categories; these individual rank scores are then aggregated to the full sample. The Friedman rank test essentially normalizes each respondent's response-say, a Very Important for "safety"-in the context of that respondent's propensity to select that response-in this case, his or her propensity to select Very Important. In cases where a respondent rates multiple attributes equally (for example, rating both nighttime safety and daytime safety as Very Important), a tie rank score (the midpoint of the tied rank range) is given to all tied attributes. Table 4 shows standardized Friedman rank scores for our transit agencies' response set. The table may be interpreted thusly: the most important attribute (in our case, safety) is assigned a value of 1 , and all other attributes' Friedman rank scores are scaled in proportion to the attribute "safety."

By and large, the rank order remains the same using this analytical method in comparison to the mean values reported in Table 3, but with a few interesting exceptions. First, using this more nuanced method we find that both of our objectives related to the interface with outside agencies become significantly more important, which is in accord with Horowitz and Thompson's findings $(1994,1995)$. The objective "minimize institutional barriers to transferring" rises from rank 8 to rank 
4 using the Friedman test. Similarly, the objective "minimize fare inconsistencies" rose in rank from position 16 to position 14. These changes reflect the high relative importance of these two attributes to some of our respondents, even given their low level of importance to others.

\section{Table 4. Average Objective Scores (Using Standardized Friedman Rank Score)}

\begin{tabular}{|c|c|c|c|}
\hline & OBJECTIVE & $\begin{array}{l}\text { STD. } \\
\text { FRIEDMAN } \\
\text { SCORE }\end{array}$ & \\
\hline 1 & Provide a safe and secure environment. & 1.00 & Gp. 1 \\
\hline 2 & Minimize pedestrian-vehicle conflicts. & 0.78 & Gp. 2 \\
\hline 3 & Maximize coordination of scheduling to accommodate transfers. & 0.71 & \multirow{10}{*}{$\begin{array}{l}\stackrel{m}{\check{0}} \\
\text { đ̃ }\end{array}$} \\
\hline 4 & $\begin{array}{l}\text { Minimize institutional barriers to transferring such as transfer fares, lack of } \\
\text { information or poor coordination of schedules. }\end{array}$ & 0.69 & \\
\hline 5 & Minimize total cost of operations (including maintenance costs). & 0.67 & \\
\hline 6 & Maximize reliability of station/stop equipment. & 0.65 & \\
\hline 7 & Provide adequate station/stop space. & 0.64 & \\
\hline 8 & $\begin{array}{l}\text { Provide a comfortable physical environment with respect to lighting, } \\
\text { temperature, and cleanliness. }\end{array}$ & 0.63 & \\
\hline 9 & Efficiently process rider flows. & 0.62 & \\
\hline 10 & Provide protection from the weather. & 0.61 & \\
\hline 11 & Maximize vehicle maneuverability (turning radii, etc). & 0.60 & \\
\hline 12 & Efficiently collect fares and control entry to station/stop/vehicle. & 0.58 & \\
\hline 13 & $\begin{array}{l}\text { Maximize operational ease at the station or facility, e.g., vehicle maintenance, } \\
\text { vehicle storage, ticketing, baggage handling, and/or accounting. }\end{array}$ & 0.50 & \multirow{11}{*}{ 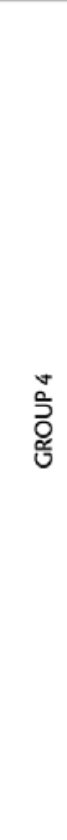 } \\
\hline 14 & $\begin{array}{l}\text { Minimize fare inconsistencies, i.e., different fare rates across transit agencies or } \\
\text { inconsistent rates across like modes. }\end{array}$ & 0.50 & \\
\hline 15 & Provide a break area for vehicle operators. & 0.48 & \\
\hline 16 & $\begin{array}{l}\text { Maximize flexibility for expansion to handle an increase in demand or } \\
\text { addition of new modes. }\end{array}$ & 0.47 & \\
\hline 17 & $\begin{array}{l}\text { Maximize joint development, i.e., involving the public and private sectors in } \\
\text { sharing the facility and its costs and revenues. }\end{array}$ & 0.45 & \\
\hline 18 & $\begin{array}{l}\text { Maximize environmental friendliness of station/facility ("green" } \\
\text { station/facility). }\end{array}$ & 0.43 & \\
\hline 19 & $\begin{array}{l}\text { Minimize wasted space in station/stop design because large spaces increase } \\
\text { construction costs and require more maintenance, security, and } \\
\text { environmental controls. }\end{array}$ & 0.41 & \\
\hline 20 & $\begin{array}{l}\text { Minimize negative impact on existing transportation services, i.e., on transit } \\
\text { agencies who cannot participate or on transit agencies whose routes are } \\
\text { disrupted or whose routes face additional competition. }\end{array}$ & 0.41 & \\
\hline 21 & Minimize queues. & 0.41 & \\
\hline 22 & Provide restrooms, first-aid supplies, and public telephones. & 0.40 & \\
\hline 23 & $\begin{array}{l}\text { Maximize income from non-transport activities, such as advertising and } \\
\text { vending. }\end{array}$ & 0.39 & \\
\hline
\end{tabular}




\section{Conclusions}

So what makes a good transit stop or station? While the literature on transit facilities lists important attributes, it collectively provides scant information on the relative importance of these attributes. To address this shortcoming, we provide a quantitative analysis of the views of a representative sample of 175 U.S. transit managers (supplemented by a smaller sample of telephone interviews) on the relative importance of a wide array of stop/station attributes. Our ranking of attributes describes the propensity of transit agencies to value one attribute more highly than others and assigns estimates of the magnitude of these propensities using a nonparametric method.

Transit agencies are not, of course, the sole arbiters of what makes a stop or station good, and they must consider the perspective of many other stakeholders-passengers, stop/station adjacent businesses/residents, local governments, etc. - in the course of their work. Overall, we find that transit agencies believe that passenger safety and security are by far the most important determinants of a good stop or station. This finding is consistent with the findings of Horowitz and Thompson $(1994,1995)$. While much of the literature on transit stops and stations has not distinguished the relative importance of passenger safety/security, our findings are consistent with behavioral studies of the "out-of-vehicle" travel experience of transit users (ITE Technical Council Committee 1992; Shayer 2004).

Following safety and security, 10 factors cluster relatively closely as important in the views of the transit managers surveyed. They are (in order): (2) pedestrian/ vehicle conflicts (Vuchic and Kikuchi 1974), (3) schedule coordination, (4) operating costs, (5) stop/station equipment reliability, (6) comfortable environment, (7) adequate stop/station space, (8), inter-agency coordination, (9) facilitation of passenger flows, (10) accommodation of vehicle movements, and (11) protection of passengers from weather.

Specifically, our findings further suggest that transit agencies tend to value useroriented attributes more highly, such as safety and seamless transferring, than non-user-oriented attributes. This may be due to the immediacy and constancy of user-related factors, while considerations such as joint development arise infrequently. Our telephone interviews amplified many of these findings. Interviewees reported examples of how safety and security concerns "trumped" all other concerns. For example, stop/station comfort (ample and comfortable seating) is often hindered by security concerns (less inviting benches that discourage sleeping). 
While many of the findings reported here are not likely to surprise anyone familiar with transit user behavioral research, respondents' strong emphasis on functional attributes-safety/security, pedestrian/vehicle conflicts, schedule coordination, etc.- suggests something quite important: that the tendency to focus on physical attributes in transit facility design (Metropolitan Transportation Commission 2006; Liu, Pendyala, and Polzin 1997) is of limited use at best, and potentially misleading at worst. Further, the overwhelming emphasis on safety among those surveyed suggests that perhaps the central determinant of transit use lies often partially, and sometimes completely, outside of the control of transit agencies.

\section{Acknowledgments}

This work was performed under the sponsorship of the State of California Business, Transportation and Housing Agency, Department of Transportation (Caltrans), Division of Research and Innovation (DR\&l). The contents of this paper reflect the views of the authors, who are responsible for the facts and the accuracy of the data presented herein. The contents do not necessarily reflect the official views or policies of the State of California. The authors thank Bruce Chapman of DR\&I for his support of this research. The authors also thank Hiroyuki Iseki of the University of Toledo and Adina Ringler, formerly of the University of California, Los Angeles, for their contributions to this research. We also extend our sincere gratitude to the many transit agency employees who participated in our survey and interviews.

\section{References}

Committee on Intermodal Transfer Facilities. 1974. Intermodal transfer facilities research needs. Transportation Research Record 505:43-46.

Demetsky, M.J., L.A. Hoel, and M.R. Virkler. 1976. Methodology for the design of urban transportation interface facilities. U.S. Department of Transportation, DOT-TST-77-46, December.

Demetsky, M.J., L.A. Hoel, and M.R. Virkler. 1977. A procedural guide for the design of transit stations and terminals. U.S. Department of Transportation, DOTTST-77-53, Washington D.C., July.

Fitzpatrick, K., K. Hall, et al. 1996. Guidelines for the location and design of bus stops. TCRP Report 19, Washington, D.C., Transportation Research Board. 
Hocking, R. J. 1990. Effectiveness of downtown transit centers. ITE Journal.

Hoel, L.A. and E.S. Rozner. 1976. Transit facility operations. Transportation Research Record 614: 1-5.

Hoel, L.A., M.J. Demetsky, and M.R. Virkler. 1994. Criteria for evaluating alternative transit station designs. U.S. Department of Transportation, DOT-TST-76-68, February.

Horowitz, A. J., and N. A. Thompson. 1994. Evaluation of intermodal passenger transfer facilities. Federal Highway Administration, U.S. Department of Transportation, DOT-T-95-02, Washington D.C.

Horowitz, A. J., and N. A. Thompson. 1995. Generic objectives for evaluation of intermodal passenger transfer facilities. Transportation Research Record 1503:104-110.

Iseki, H., and B.D. Taylor. 2007. Not all transfers are created equal: Toward a framework relating transfer connectivity to travel behavior. Paper 07-1905 in CD-ROM of 86th Annual Meeting of the Transportation Research Board, Washington D.C., January.

ITE Technical Council Committee 5C-1A. 1992. The location and design of bus transfer facilities. ITE Journal: 33-37.

Law, P., and B. D. Taylor. 2001. Shelter from the storm: Optimizing the distribution of bus stop shelters in Los Angeles. Journal of the Transportation Research Board 1753: 79-85.

Liu, R., R.M. Pendyala, and S. Polzin. 1997. Assessment of intermodal transfer penalties using stated preference data. Transportation Research Record1607: 74-80.

Metropolitan Transportation Commission. 2006. Transit connectivity study.

Shayer, Y. 2004. Intermodal transfer comparison between the user and the supplier points of view. Paper in CD-ROM of 83rd Annual Meeting of the Transportation Research Board, Washington D.C., January.

Vuchic, V. R., and S. Kikuchi. 1974. Design of outlying rapid transit station areas. Transportation Research Record 505:1-12. 


\section{About the Authors}

MiCHAEL SMART (msmart@ucla.edu) is a third-year doctoral student at UCLA. His research interests include transportation and social equity, access to the labor market, and travel behavior. He has recently completed an analysis of the SAFETEA-LU earmarking process and is currently working on a detailed look at carpooling among immigrant communities. He graduated with a master's degree in City Planning from the University of Pennsylvania in Philadelphia and has previously worked at the University of Minnesota Law School's Institute on Race and Poverty.

MARK A. Miller (mamiller@path.berkeley.edu) is a Research Specialist at the California PATH (Partners for Advanced Transit and Highways) Program at the University of California, Berkeley where he has worked more than 19 years. His research has focused on developing evaluation frameworks and methodologies and performing impact assessments of intelligent transportation systems (ITS) technologies in the setting of field tests and case studies. His work experience has been well balanced between quantitative and qualitative investigations covering both technical and non-technical (deployment, societal, and institutional issues) aspects of ITS. He has significant work experience in the areas of transit operations research and policy and behavioral research, including bus rapid transit, and commercial vehicle operations.

BRIAN D. TAYLOR (btaylor@ucla.edu) is a Professor and Chair of Urban Planning and Director of the Institute of Transportation Studies at UCLA. His research centers on both transportation finance and travel demographics. He has examined the politics of transportation finance, including the influence of finance on the development of metropolitan freeway systems and the effect of public transit subsidy programs on both system performance and social equity. His research on the demographics of travel behavior has emphasized access-deprived populations, including women, racial-ethnic minorities, the disabled, and the poor. His work in this area has also explored the relationships between transportation and urban form, with a focus on commuting and employment access for low-wage workers. 